\title{
NATRIUM DALAM DARAH TENAGA KERJA SEBELUM DAN SESUDAH TERPAPAR PANAS (STUDI KASUS DI BAGIAN BUFFING PROCESS PT YAMAHA MUSICAL PRODUCTS INDONESIA PASURUAN TAHUN 2015)
}

\author{
Vebrin Arsintha Tungga Dewi, Demes Nurmayanti, Ngadino
}

\begin{abstract}
Excessive exposure to heat resulting heat cramps, heat exhaustion and heat stroke. Workers who have not been acclimatized to hot temperatures are usually sweat more than usual. In this condition, human will lose body fluids and electrolytes. The purpose of this study analyzes the differences of sodium level in the blood of workers before and after exposure to heat.

This is an observational analytic research with cross sectional approach. Data was obtained from the measurement result with total population of 15 workers and sample of 14 workers. The data was analyzed analytically by using Paired Sample $T$ Test.

The results shows that all workers aged less than 40 years with working period of less than five years and most of whom indicated normal nutritional status. The company has conducted engineering controls, administrative and PPE. $P$ value was $\leq 0.01$ and result of paired $t$ test revealed highly significant.

The Conclusion underlines difference in the level of sodium in workers' blood before and after exposure to heat for 2.5 hours.

Installation of local exhaust ventilation as well as the training of labor on heat stress and prevention is suggested.

Keywords: working climate, sodium in the blood
\end{abstract}

\section{PENDAHULUAN}

Seiring dengan kemajuan teknologi, industri di Indonesia dari tahun ke tahun semakin bertambah dan berkembang. Dalam suatu lingkungan kerja, tenaga kerja akan menghadapi berbagai risiko. Dimana risiko itu bisa berasal dari pekerja itu sendiri, mesin maupun dari lingkungan sekitar. Tekanan panas merupakan faktor lingkungan fisik yang dalam kondisi tertentu dapat menyebabkan kerugian pada tenaga kerja.

Tempat kerja yang nyaman dan aman merupakan salah satu faktor penunjang kelancaran dalam bekerja. Lingkungan kerja yang panas dan lembab akan menurunkan produktivitas kerja, juga membawa dampak negatif terhadap kesehatan dan keselamatan kerja.

Paparan suhu tinggi dapat mengakibatkan diantaranya heat cramps, heat exhaustion, dan heat stroke.Heat exhaustion biasanya terjadi akibat cuaca yang cukup panas, terutama bagi tenaga kerja yang masih belum beraklimatisasi terhadap paparan suhu panas. Tenaga kerja biasanya berkeringat banyak tidak seperti biasanya, sedangkan suhu badan normal maupun subnormal. Begitu juga tekanan darah menurun, denyut nadi lebih cepat daripada biasanya. Tenaga kerja yang terpapar panas akan merasa cepat lelah.Pada kondisi tersebut, cairan tubuh dan elektrolit akan hilang karena digunakan untuk menjaga tubuh tetap dalam keadaan suhu normal.
Berdasarkan hasil survei pendahuluan yang dilakukan penulis di Bagian Proses Penghilang Goresan, pada saat melakukan pengukuran ISBB di bagian Proses Penghilang Goresan melebihi NAB menurut Peraturan Menteri Tenaga Kerja dan Transmigrasi Republik Indonesia Nomor PER.13/MEN/X/2011merupakan tempat untuk menghilangkan goresan serta mengkilapkan goresan dengan menggunakan mesin putar terus-menerus dapat menghasilkan panas. Di dalam ruang penghilang goresan terdapat tekanan panas yang cukup tinggi akibat putaran mesin yang terus-menerus sehingga suhu di dalam ruangan tersebut menjadi panas. Akibat resiko tersebut tenaga kerja mudah berkeringat dan cepat haus maupun lelah.

Tujuan penelitian ini untuk menganalisis perbedaan natrium dalam darah sebelum dan sesudah terpapar panas di Bagian Proses Penghilang Goresan Tahun 2015.

\section{METODE PENELITIAN}

Jenis Penelitian adalah penelitian analitik observasional dengan pendekatan cross sectional . Objek Penelitian semua tenaga kerja di bagian Proses Penghilang Goresan sebanyak 14 tenaga kerja.

Metode pengumpulan data dalam penelitian ini adalah pengukuran natrium dalam darah menggunakan Electrolyte Auto 
Analyzer, pengukuran ISBB menggunakan Wet Bulb Globe Temperature dan observasi lingkungan sekitar.

Analisis data yang digunakan untuk menganalisis perbedaan natrium dalam darah tenaga kerja sebelum dan sesudah terpapar panas dengan menggunakan uji Paired Samples T Test untuk mengetahui seberapa signifikan perbedaannya.

\section{HASIL PENELITIAN DAN PEMBAHASAN}

\section{Faktor Tenaga Kerja}

a. Umur

Umur produktif tenaga kerja dalam suatu perusahaan rata-rata 21-40 tahun. Umur tenaga kerja dapat dilihat pada tabel dibawah ini :

Tabel IV.1

DISTRIBUSI RESPONDEN BERDASARKAN UMUR DI BAGIAN PROSES PENGHILANG GORESAN TAHUN 2015

\begin{tabular}{|c|c|c|c|}
\hline No & Umur & $\mathrm{N}$ & $\%$ \\
\hline 1 & Kurang dari sama dengan 40 tahun & 14 & 100 \\
\hline 2 & Lebih dari 40 tahun & 0 & 0 \\
\hline \multicolumn{2}{|c|}{ Jumlah } & 14 & 100 \\
\hline
\end{tabular}

Sumber : Data Primer

Hasilnya bahwa tenaga kerja secara keseluruhan berumur $\leq 40$ tahun dengan rata-rata umur tenaga kerja 22 tahun.Menurut WHO 1969 daya tahan tubuh terhadap tekanan panas akan terjadi penurunan pada umur yang lebih tua. Orang yang umurnya lebih tua akan lambat keluar keringatnya dibanding dengan orang yang lebih muda, dikarenakan orang yang lebih tua membutuhkan waktu yang lebih lama dalam mengembalikan suhu tubuh menjadi normal setelah terpapar panas. Apabila tenaga kerja yang lebih tua bekerja di bagian lingkungan kerja yang panas maka dapat menyebabkan Heat Stroke.

b. Masa Kerja

Tenaga kerja mempunyai kepuasan kerja yang terus meningkat sampai lama kerja 5 tahun. Masa kerja tenaga kerja dapat dilihat pada tabel dibawah ini

Tabel IV.2

DISTRIBUSI RESPONDEN BERDASARKAN MASA KERJA DI BAGIAN PROSES PENGHILANG GORESAN TAHUN 2015

\begin{tabular}{|c|c|c|c|}
\hline No & Masa Kerja & $\mathrm{N}$ & $\%$ \\
\hline 1 & Kurang dari sama dengan 5 tahun & 13 & 92,9 \\
\hline 2 & Lebih dari 5 tahun & 1 & 7,1 \\
\hline & Jumlah & 14 & 100 \\
\hline
\end{tabular}

\section{Sumber : Data Primer}

Berdasarkan hasil penelitian diatas bahwa sebagian besar masa kerja kurang dari 5 tahun. Masa kerja yang pendek dapat mempengaruhi tubuh dalam penerimaan

c. Status Gizi

Status gizi digunakan untuk mengetahui ukuran tubuh setiap manusia. Status gizi tenaga kerja dapat dilihat pada tabel dibawah ini : panas lingkungan kerja, semakin lama tenaga kerja terpapar panas di suatu lingkungan tempat kerja maka tubuh dapat beradaptasi terhadap panas. 
Tabel IV.3

DISTRIBUSI RESPONDEN BERDASARKAN STATUS GIZI DI PROSES PENGHILANG GORESAN 2015

\begin{tabular}{|c|c|c|c|}
\hline No & Status Gizi & $\mathrm{N}$ & $\%$ \\
\hline 1 & Underweight & 2 & 14,3 \\
\hline 2 & Normal & 12 & 85,7 \\
\hline 3 & Overweight & 0 & 0 \\
\hline 4 & Obese & 0 & 0 \\
\hline & Jumlah & 14 & 100 \\
\hline
\end{tabular}

Sumber : Data Primer

Berdasarkan hasil menunjukkan bahwa sebagian besar tenaga kerja berstatus gizi normal. Adanya perbedaan ukuran tubuh setiap manusia

maka akan mempengaruhi reaksi fisiologis manusia terhadap tekanan panas.

\section{Iklim Kerja Indeks Suhu Bola} dan Basah serta Pengendaliannya

Hasil pengukuran ISBB di Bagian Proses Penghilang Goresan, yaitu $30,2^{\circ} \mathrm{C}$ dengan waktu kerja 8 jam/hari, dikategorikan dalam beban kerja yang sedang, tidak memenuhi syarat berdasarkan Peraturan Menteri Tenaga Kerja dan Transmigrasi Republik Indonesia Nomor PER.13/MEN/X/2011. Kategori beban kerja sedang kegiatannya yaitu berdiri, mengangkat atau mendorong beban yang beratnya sedang dan menaikkan barang berat secara terputu-putus misalnya menyekop.

Panas berlebih sangat beresiko menyebabkan gangguan kesehatan. Luas ruangan yang sempit dihuni banyak tenaga kerja terdapat banyak mesindapat menimbulkan panasyang berlebih sehingga tenaga kerja berkeringat tidak seperti biasanya, mudah cepat lelah dan haus. Walaupun sudah ada pemasangan $\mathrm{AC}$ dan ventilasi digunakan untuk pengendalian suhu, pengendalian kelembaban, dan pengendalian kebauan namun ISBB yang dihasilkan dari ruangan tersebut masih melebihi NAB. Sehingga perlu adanya pengendalian yang lebih efektif

\section{Analisa Natrium dalam Darah Tenaga Kerja}

a. Natrium dalam darah sebelum bekerja Natrium dalam tubuh sangat berperan penting dalam keseimbangan air, hantaran impuls saraf serta kontraksi otot. seperti pemasangan local exhaust ventilation yang bertujuan untuk mengendalikan panas konveksi yaitu dengan menghisap keluar udara yang panas melalui canopy hood.

Pengendalian secara administratif yaitu dengan adanya perputaran waktu kerja atau rotasi kerja, penyediaan air minum, pemasangan poster APD, pengukuran ISBB yang dilakukan setiap 6 bulan sekali, dan pemeriksaan kesehatan setiap 1 tahun sekali. Perlu adanya training terhadap tenaga kerja tentang heat stress dan pencegahannya. Heat stressadalah beban yang diterima oleh tenaga kerja seperti suhu yang panas, kelembaban, panas radiasi. Efek dari beban yang diterima oleh tenaga kerja disebut dengan Heat strain, efeknya adalah suhu tubuh naik, denyut nadi naik, tekanan darah menurun dan jumlah keringat yang keluar meningkat. Apabila keringat yang dikeluarkan meningkat didalam keringat mengandung natrium dan klorida maka dapat menyebabkan hiponatremia yaitu kekurangan natrium. Tanda dan gejalanya mual, muntah, sakit kepala, lelah, letih, kehilangan nafsu makan, otot lemah, kram dan tingkat kesadaran menurun. APD yang digunakan oleh tenaga kerja tidak ada APD khusus untuk panas, karena panas yang dihasilkan dari ruangan tersebut tidak terlalu ekstrim. 
Tabel IV.4

ANALISA NATRIUM DALAM DARAH SEBELUM BEKERJA DI BAGIAN PROSES PENGHILANG GORESAN TAHUN 2015

\begin{tabular}{|c|c|c|c|}
\hline No & Ion Elektrolit $\left(\mathrm{Na}^{+}\right)$sebelum bekerja & $\mathrm{N}$ & $\%$ \\
\hline 1 & Normal & 14 & 100 \\
\hline 2 & Tidak normal & 0 & 0 \\
\hline \multicolumn{2}{|c|}{ Jumlah } & 14 & 100 \\
\hline
\end{tabular}

Sumber : Data Primer

Natrium dalam darah tenaga kerja sebelum bekerja dapat diketahui bahwa secara keseluruhan natrium normal. Hal ini dikarenakan tenaga kerja tersebut masih dalam kondisi yang segar dan belum mendapatkan beban.

b. Natrium dalam darah sesudah bekerja Pengukuran natrium dalam darah tenaga kerja dilakukan setelah tenaga kerja bekerja 2,5 jam.

Tabel IV.5

ANALISA NATRIUM DALAM DARAH SESUDAH TENAGA KERJA BEKERJA DI BAGIAN PROSES PENGHILANG GORESAN TAHUN 2015

\begin{tabular}{|c|c|c|c|}
\hline No & Ion Elektrolit $\left(\mathrm{Na}^{+}\right)$sesudah bekerja & $\mathrm{N}$ & $\%$ \\
\hline 1 & Normal & 7 & 50 \\
\hline 2 & Tidak normal & 7 & 50 \\
\hline \multicolumn{2}{|c|}{ Jumlah } & 14 & 100 \\
\hline
\end{tabular}

Sumber : Data Primer

Natrium dalam darah sesudah bekerja selama 2,5 jam separuh responden kadar natrium dalam tubuh tenaga kerja mengalami penurunan. Tenaga kerja terpapar panas sehingga menyebabkan banyaknya pengeluaran keringat tubuh. Bersamaan dengan keluarnya keringat tubuh kehilangan sejumlah garam mineral sehingga dapat mengurangi konsentrasi elektrolit dalam tubuh.

\section{Analisa Data Paired Sample T Test}

Menganalisa natrium dalam darah tenaga kerja sebelum dan sesudah terpapar panas.

TABEL IV.6

PAIRED SAMPLES TEST

\begin{tabular}{|l|c|c|c|c|c|c|c|}
\hline & \multirow{2}{*}{$\mathrm{N}$} & \multirow{2}{*}{ Correlation } & \multicolumn{5}{|c|}{ Paired Differences } \\
\cline { 4 - 7 } & & & Sig & Mean & Std & $\mathrm{df}$ & Sig.(2-tailed) \\
\hline $\begin{array}{l}\text { Pair 1 NaSBLM- } \\
\text { NaSSDH }\end{array}$ & 14 & 0,904 & 0,000 & 3,357 & 0,633 & 13 & 0,000 \\
\hline
\end{tabular}

Sumber : Data Primer

Hasil Penelitian natrium dalam darah tenaga kerja sebelum dan sesudah terpapar panas terjadi perbedaan yang sangat signifikan. Panas merupakan beban

\section{KESIMPULAN}

Dapat disimpulkan bahawa area Proses Penghilang Goresan diketahui : Faktor tenaga kerja umur responden semua tenaga kerja berumur $\leq 40$ tahun, dengan masa kerja responden sebagian besar $\leq 5$ tahun dan memliki status gizi yang normal. Iklim kerja indeks suhu basah dan bola yang dihasilkan di bagian Proses Penghilang bagi tenaga kerja yang menyebabkan banyaknya pengeluaran cairan tubuh melalui keringat.

Goresan melebihi NAB setinggi $30,2^{\circ} \mathrm{C}$. Natrium dalam darah tenaga kerja sebelum bekerja semuanya normal dan sesudah bekerja separuh dari responden mengalami penurunan natrium. Upaya pengendalian panas yang telah diterapkan oleh perusahaan meliputi pengendalian teknik, administratif dan alat pelindung diri. Namun dari beberapa pengendalian tersebut masih ada kekurangan sehingga perlu adanya 
penambahan pengendalian, baik pengendalian teknik, administratif maupun APD. Ada perbedaan kadar natrium dalam darah tenaga kerja sebelum dan sesudah terpapar panas.

\section{SARAN}

Perlu adanya pemasangan local exhaust ventilation yang bertujuan untuk mengendalikan panas konveksi yaitu dengan menghisap keluar udara yang panas melalui canopy hood yang dipasang diatas sumber panas dengan bantuan alat mekanis (fan) atau secara alami yaitu udara yang panas akan mengembang dan kemudian akan naik keatas dan kemudian melalui canopy hood udara panas tersebut akan terhisap keluar. Perlu adanya training terhadap tenaga kerja tentang heat stress dan pencegahannya.

\section{DAFTAR PUSTAKA}

Anizar, 2010. Teknik Keselamatan dan Kesehatan Kerja di Industri. Jakarta : Graha Ilmu

Budiyono, S. 2011. Anatomi Tubuh Manusia. Jakarta : Laskar Aksara

Karlina, Dewi. 2013. Keterampilan Dasar Keperawatan Klinis. Yogyakarta : Imperium

Kuswana, W, S. 2014. ERGONOMI dan K3 (Kesehatan Keselamatan Kerja). Jakarta : Remaja Rosda Karya

Maurits, L, M, S, K. 2010. Selintas Tentang Kelelahan Kerja. Yogyakarta : Amara Books
Niman, Susanti. 2013. Pengkajian Kesehatan Untuk Perawat. Jakarta : CV. Trans Info Media

Notoatmodjo, Soekidjo. 2010. Metodologi Penelitian Kesehatan. Jakarta : Rineka Cipta

Peraturan Menteri Tenaga Kerja dan Transmigrasi Republik Indonesia Nomor PER.13/MEN/X/2011

Ramli, S. 2010. Sistem Manajemen Keselamatan dan Kesehatan Kerja OHSAS 18001. Jakarta : Dian Rakyat

Saifuddin. 2011. Atlas Berwarna Tiga Bahasa: Anatomi Tubuh Manusia. Jakarta : Salemba Empat.

Sofro, A, S, M. 2012. Darah. Yogyakarta : Pustaka Pelajar.

Suma'mur, P, K. 2013. Hygiene Perusahaan dan Kesehatan Kerja (HIPERKES) Edisi 2. Jakarta : CV Sagung Seto

Suwartono. 2014. Dasar-dasar Metodologi Penelitian. Jakarta : Andi Publisher

Wibowo, A. 2014. Metodologi Penelitian Praktis Bidang Kesehatan. Jakarta : Rajawali Press 